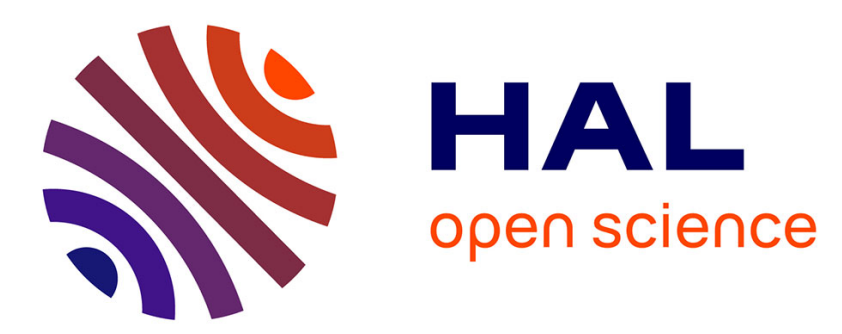

\title{
Shear-Induced Exothermic Chemical Reactions
}

H. Chen, V. Nesterenko, J. Lasalvia, M. Meyers

\section{To cite this version:}

H. Chen, V. Nesterenko, J. Lasalvia, M. Meyers. Shear-Induced Exothermic Chemical Reactions. Journal de Physique IV Proceedings, 1997, 07 (C3), pp.C3-27-C3-32. 10.1051/jp4:1997307 . jpa00255380

\section{HAL Id: jpa-00255380 https://hal.science/jpa-00255380}

Submitted on 1 Jan 1997

HAL is a multi-disciplinary open access archive for the deposit and dissemination of scientific research documents, whether they are published or not. The documents may come from teaching and research institutions in France or abroad, or from public or private research centers.
L'archive ouverte pluridisciplinaire HAL, est destinée au dépôt et à la diffusion de documents scientifiques de niveau recherche, publiés ou non, émanant des établissements d'enseignement et de recherche français ou étrangers, des laboratoires publics ou privés. 


\title{
Shear-Induced Exothermic Chemical Reactions
}

\author{
H.C. Chen, V.F. Nesterenko, J.C. LaSalvia* and M.A. Meyers
}

Department of Applied Mechanics and Engineering Sciences, University of California, San Diego La Jolla, CA 92093, U.S.A.

*U.S. Army Research Laboratory, Aberdeen Proving Ground, Aberdeen, Maryland 21005, U.S.A.

\begin{abstract}
The structure of controlled high-strain-rate shear bands generated in Ti-Si reactive powders bas been investigated by means of the radial symmetric collapse of a thick-walled cylinder. Shear localization developed at global strains of 0.2-0.4 and a strain rate of $10^{4} \mathrm{~s}^{-1}$. Within the shear bands, local shear strains were up to 100 and local shear strain rates were $10^{7} \mathrm{~s}^{-1}$. Chemical reactions were initiated at these shear bands and propagated throughout the entire specimen under critical global strain conditions. A model for a periodic distribution of "hot spots" in reactive powders is proposed. It is possible to estimate the reaction rate from the triangular unreacted regions formed by the shear localization process.
\end{abstract}

Résumé. La structure de bandes de cisaillement crées dans des poudres reactives Ti-Si a étée étudiée avec le collapse symmétrique d'un cylindre de parois épaisse. Les bandes de cisaillement se forment à des déformations globales de 0.2-0.4 à une vitesse de deformation de $10^{4} \mathrm{~s}^{-1}$ Dans les bandes de cisaillement les déformations de cisaillement atteignent des valeurs jusqu'a 100 et la vitesse de déformation est $10^{7} \mathrm{~s}^{-1}$. Les réactions chimiques sont initiées dans ces bandes de cisaillement. Leur propagation dans l'échantillion demande une déformation globale critique. La modélisation des bandes de cisaillement avec la reaction des poudres reactives est proposée. Il est possible d'éstimer le taux de réaction à partir de régions triangulaires formées par les bandes de cisaillement dans lesquelles il n'y a pas eu de réaction.

\section{INTRODUCTION}

The importance of shear deformation on chemical reactions was first demonstrated by Bridgman [1], and this was reemphasized by Vereshchagin et al. [2], Teller [3] and Enikolopyan et al. [4]. Under shock conditions, Dremin and Breusov [5] suggested that shear can assist chemical reactions and proposed the "ROLLER" model to explain this phenomenon. Recently, shock densification experiments conducted on $\mathrm{Mo}-\mathrm{Si}$, or $\mathrm{Nb}-\mathrm{Si}$ powder mixtures by $\mathrm{Yu}$ et al. [6], and Meyers et al. [7] and Nesterenko et al. [8-10] revealed the formation of localized reactions in nonuniformly deformed areas. These studies also showed that the powder mixtures intensely deformed in localized regions underwent chemical reaction even at pressures lower than the shock threshold pressure. Nesterenko et al. [8-10] carried out controlled shear experiments at a shock pressure lower than $1 \mathrm{GPa}$ and demonstrated that intense shear deformation can initiate chemical reaction. The objectives of this research are: (a) to establish the shear-induced chemical reactions, and (b) to find the threshold global strains which can initiate shear localization and which can trigger and propagate the chemical reactions. To achieve these purposes, the controlled high-strain, highstrain-rate experiments [8-11] were conducted to generate shear localization by varying global strains. Ti-Si reactive powder mixtures were used to investigate the chemical reactions under shear localization, because of their exothermic heat which can sustain the reactions.

\section{EXPERIMENTAL PROCEDURES}

A Ti-Si $(74 \mathrm{wt} \%-26 \mathrm{wt} \%)$ powder mixture in its stoichiometric composition of the intermetallic compound $\mathrm{Ti}_{5} \mathrm{Si}_{3}$ was used in this research. The powders (from CERAC) had sizes of $\sim 325$ mesh $(<44 \mu \mathrm{m}$ ), high purity (99.5\% for Ti; $99.9 \%$ for $\mathrm{Si}$ ) and irregular shape. The thick-walled cylinder (TWC) method [8-11] was applied for this investigation. The experimental configuration was used to generate controlled and prescribed shear localization in porous samples. The porous powders were initially placed in a tubular cavity between a central copper rod (diameter $\sim 16 \mathrm{~mm}$ ) and an outer copper tube (inner diameter $\sim 20 \mathrm{~mm}$ 
and outer diameter $\sim 31 \mathrm{~mm}$ ). The first explosive (mixture of ammonite and sand in 3:1 volume ratio) with low detonation velocity $(-2.5 \mathrm{~km} / \mathrm{s})$ was used to densify the powder. No significant shear localization was observed after this stage because the global deformation is sufficiently small (final diameter of inner surface of driving copper cylinder is equal to $18 \sim 19 \mathrm{~mm}$ ). This stage produced mainly the densification of the powder. An orifice with diameter $11 \mathrm{~mm}$ was drilled along the longitudinal axis of copper rod and is cylindrical copper stopper rod was inserted in the central orifice. This composite cylinder was deformed by the detonation of a second cylindrical explosive charge (ammonite) with a detonation velocity of 4.0 $\mathrm{km} / \mathrm{sec}$, an initial density of $1 \mathrm{~g} / \mathrm{cm}^{3}$, and an outer diameter of $60 \mathrm{~mm}$. This second explosive event produced significant plastic deformation in densified porous layer which was highly localized in sheal bands and not homogeneously distributed.

\section{RESULTS AND DISCUSSION}

Four different deformation levels were applied in the second explosive event; global strains of $0.23,0.32$. 0.35 , and 0.37 were obtained. The global strains and strain rates for Ti-Si powder mixtures layers can be obtained quantitatively from the strains in compressible copper shell driving the homogeneous deformation process [8-10]. Table 1 shows the global strains of the inner layers with different sized stoppers. Profusc shear localization can be seen in samples with $\varepsilon \sim 0.32,0.35$, and 0.37 , but not with $\varepsilon \sim 0.23$. The globil view of shear localization after deformation stage is shown in Figures 1. The local shear strain is the rittiu of the displacement, $\Delta$, and the thickness of the shear band, $\delta[8-10]$. Local shear strains vary between 10 and 100 , approximately.

The microstructural observations for Ti-Si system are shown in Figures 2. After the second explosivi eventwith varying deformation conditions, the structures are quite different. Although there are no well developed shear bands at $\varepsilon \sim 0.23$, small localized regions of shear concentration were observed (Fig. 2(a)). This phenomenon is probably due to material nonuniformity or fracture of Si particles. Figs. 2(b), (c) present the typical shear band structure for $\varepsilon \sim 0.32$ and 0.35 , respectively. At $\varepsilon \sim 0.32$ and 0.35 , partial reaction was found only inside shear localization regions (shown by arrows in Figs. 2(b), (c)). Fracturing and extensive plastic flow of Ti particles inside shear localization regions is similar to the Nb-Si system 18 10]. In some experimental results at $\varepsilon \sim 0.37$, the reaction propagated throughout the whole specimen (Fig 2(d)) except the triangular area produced by discontinuity in displacement due to shear localization (Fig. 1(b)). Only cracks were left as the main feature of shear localization, as a result of solidification and shrinkage of molten reacted products. The unreacted triangular area is due to rapid heat extraction by the copper walls at an angle of $45^{\circ}$. The $\mathrm{x}$-ray diffraction pattern for the fully reacted specimen is shown in Figure 3 and the reacted products were confirmed as $\mathrm{Ti}_{5} \mathrm{Si}_{3}$. The melting point of $\mathrm{Ti}_{5} \mathrm{Si}_{3}$ is $2403 \mathrm{~K}$; the reaction is initiated inside the shear localization regions, and the heat in the environment of shear regions must be higher than $2403 \mathrm{~K}$. This high local temperature is due to the heat transferred from plastic work and released from chemical reaction. This increase in temperature from plastic work $\Delta T_{s}$ can be estimated by:

$$
\Delta \mathrm{T}_{\mathrm{s}}=\frac{1}{\rho \mathrm{C}_{\mathrm{pl}}} \int_{0}^{\gamma} \tau \mathrm{d} \gamma
$$

where $\rho$ and $C_{p 1}$ are the initial density and heat capacity of unreacted densified powder; they are equal $\left.t\right)$ $3.85 \mathrm{~g} / \mathrm{cm}^{3}$ and $0.57 \mathrm{~J} / \mathrm{g}$, respectively. The shear stress, $\tau$, was equal to approximately $0.5 \mathrm{GPa}[9]$ and thermal softening was ignored. If the local shear strain is 20 , then the plastic work is equal to $1170 \mathrm{~J} / \mathrm{g}$ and $\Delta \mathrm{T}_{\mathrm{s}}$ is equal to $2100 \mathrm{~K}$. This temperature is higher than the melting point of silicon $(1700 \mathrm{~K})$. Meyers $e t$ al. [12] and Vecchio et al. [13] considered this temperature as the initiation temperature for reaction in shock compression.

Assuming that the reaction is adiabatic and the process is initiatedat $1700 \mathrm{~K}$ :

$$
-\Delta H_{1700}=\int_{1700}^{T_{m}} C_{p 2} d T+L_{m}+\int_{T_{m}}^{T_{p d}} C_{p 3} d T, \quad T_{a d}>T_{m}
$$

where $\Delta \mathbf{H}_{1700}(\approx-247 \mathrm{~kJ} / \mathrm{mole})$ is the heat of reaction at $1700 \mathrm{~K}, \mathrm{~T}_{\mathrm{m}}(\approx 2403 \mathrm{~K})$ is the melting point of product $\mathrm{Ti}_{5} \mathrm{Si}_{3}, \mathrm{~L}_{\mathrm{m}}(\approx 25.6 \mathrm{~kJ} / \mathrm{mole})$ is the latent heat of fusion for $\mathrm{Ti}_{5} \mathrm{Si}_{3}, \mathrm{C}_{\mathrm{p} 2}\left(\approx 196.44+0.045 \mathrm{~T}-2 \times 10^{6} / \mathrm{T}^{2}\right.$

Table 1: Global strain for Ti-Si mixture

\begin{tabular}{ccccc}
\hline Diameter of copper stopper $(\mathrm{mm})$ & 6 & 3 & 1.5 & 0 \\
\hline Global strain $\varepsilon$ & 0.23 & 0.32 & 0.35 & 0.37 \\
\hline
\end{tabular}




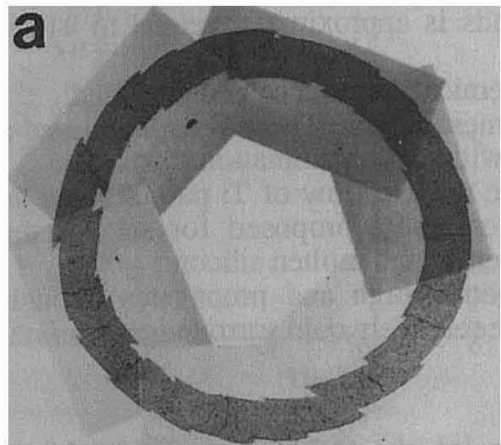

$5 \mathrm{~mm}$

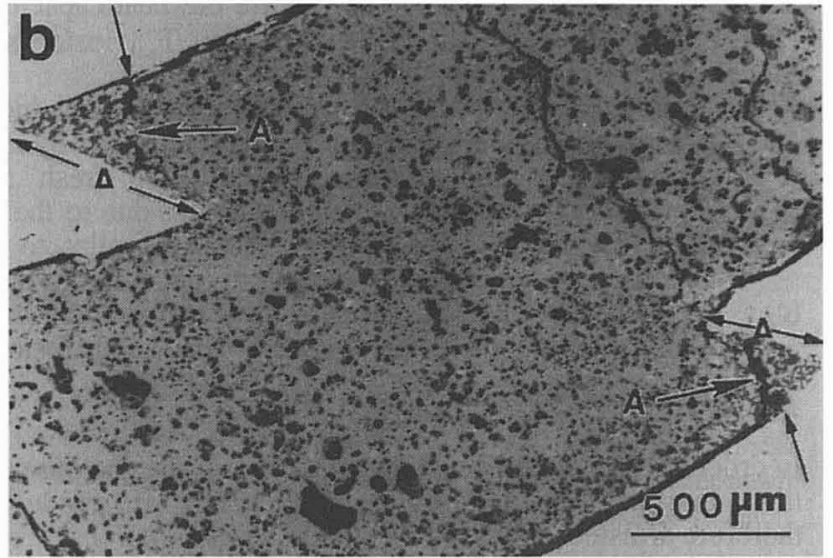

Figure 1: (a) Global view of Ti-Si mixture layer after deformation $(\varepsilon \sim 0.37)$; (b) close-up of shear localization region with displacement, $\Delta$.
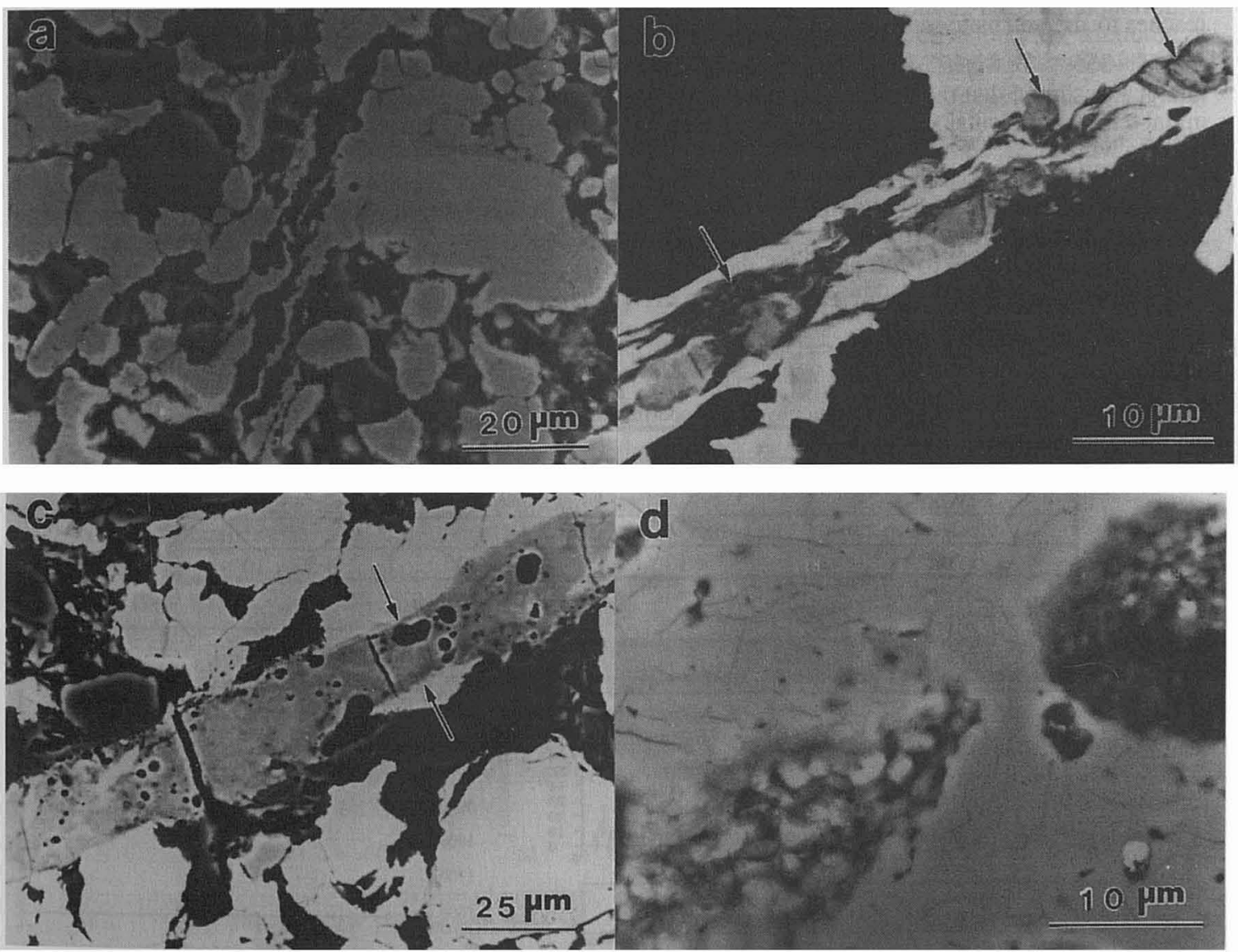

Figure 2: Deformed Ti-Si mixtures under global strain: (a) $\sim 0.23$; (b) $\sim 0.32$; (c) $\sim 0.35$; and (d) $\sim 0.37$ 
$\mathrm{J} / \mathrm{mole} \cdot \mathrm{K})$ and $\mathrm{C}_{\mathrm{p} 3}(\approx 42.2 \mathrm{~J} /$ mole $\cdot \mathrm{K})$ are the heat capacities of solid and liquid phase $\mathrm{Ti}_{5} \mathrm{Si}_{3}$, respectivcly [14]. The calculated adiabatic temperature, $\mathrm{T}_{\text {ad }}$, inside shear bands is approximately equal to $4100 \mathrm{~K}$. higher than the melting point of $\mathrm{Ti}_{5} \mathrm{Si}_{3}$.

According to the observations, a mechanism of shear-induced chemical reaction can be proposed:

(a) Ti particles are multifractured and split into foils by localized mesoshears. These foils are heated as a result of intense shear deformation and have "fresh" surfaces without contamination by oxides.

(b) Si particles are molten and reaction begins due to the extensive relative flow of Ti particles and those molten Si inside shear bands. This is similar to the Roller model proposed for shock-induced reactions [5]. The reaction proceeds along the interface between Ti and molten silicon.

(c) Reaction continues in places where temperatures are sufficiently high and propagates throughout entire specimen, then is quenched by thermal diffusion into the relatively cold surrounding materials.

\section{REACTION RATE ANALYSIS}

In order to estimate the reaction rate, one can use the unreacted triangles, shown by arrows in Fig. 1(b). In these unreacted triangular regions, the reaction rate was lower than the rate of heat loss and the reaction wils therefore arrested. Thus, $\partial \mathrm{T} / \partial \mathrm{t}$ should be less than 0 . From the conservation of energy, one can obtain:

$$
\frac{\partial \mathrm{T}}{\partial \mathrm{t}}=\alpha \frac{\partial^{2} \mathrm{~T}}{\partial \mathrm{x}^{2}}+\frac{\mathrm{Q}}{\mathrm{C}_{\mathrm{p}}} \frac{\partial \eta}{\partial \mathrm{t}}<0, \quad \frac{\mathrm{Q}}{\mathrm{C}_{\mathrm{p}}} \frac{\partial \eta}{\partial \mathrm{t}}<-\alpha \frac{\partial^{2} \mathrm{~T}}{\partial \mathrm{x}^{2}}, \quad \dot{\mathrm{Q}}_{\mathrm{r}}=\mathrm{Q} \frac{\partial \eta}{\partial \mathrm{t}}<-\alpha \mathrm{C}_{\mathrm{p}} \frac{\partial^{2} \mathrm{~T}}{\partial \mathrm{x}^{2}}
$$

where $C_{p}$ is the heat capacity $(\mathrm{J} / \mathrm{kg} \cdot \mathrm{K}), \alpha$ is the thermal diffusivity $\left(\mathrm{m}^{2} / \mathrm{s}\right),\left(\alpha=\mathrm{k} / \rho \mathrm{C}_{\mathrm{p}}\right.$, $\mathrm{k}$ is the thermal conductivity $(\mathrm{W} / \mathrm{m} \cdot \mathrm{K})$ ), $\eta$ is the degree of conversion, $\dot{Q}_{r}$ is the reaction rate. When the temperature reaches to the adiabatic temperature $\mathrm{T}_{\mathrm{ad}}$, the reaction rate $\dot{Q}_{\mathrm{r}}$ is maximum [15]. The adiabatic temperaturc for $5 \mathrm{Ti}+3 \mathrm{Si} \rightarrow \mathrm{Ti}_{5} \mathrm{Si}_{3}$ is $2403 \mathrm{~K}$ for the heat of reaction at $298 \mathrm{~K}$ [16]. Therefore, to estimate the reaction rate, it is assumed that the unreacted triangle consists of a $5 \mathrm{Ti}+3 \mathrm{Si}$ powder mixture at $2403 \mathrm{~K}$ because the initial temperature outside shear bands is $298 \mathrm{~K}$; the temperature in copper is $298 \mathrm{~K}$; and the fully reacted regions with $\mathrm{Ti}_{5} \mathrm{Si}_{3}$ compound is at $2403 \mathrm{~K}$. In this case, only heat transfer is considered to calculate the cooling rate for this triangle region. The thermophysical properties are listed on Table $2[16,17]$. Fig. 4 shows the calculated results at point $\mathrm{A}$ in this region [18]. Points A marked the boundaries between reacted and unreacted regions. From the calculated temperature-time curve (Fig. 4), one can estimate the cooling rates; this corresponds to the slope of the curve. The cooling rate varies as a function of time and is maximum at the inflection point of the curve in Fig. 4. The rate of heat loss $\dot{Q}_{\text {loss }}$ is:

$$
\dot{\mathrm{Q}}_{\text {loss }}=\mathrm{C}_{\mathrm{p}} \frac{\partial \mathrm{T}}{\partial \mathrm{t}}, \quad \dot{\mathrm{Q}}_{\mathrm{r}}<-\dot{\mathrm{Q}}_{\text {loss }}
$$

Table 2 Thermophysical properties for $\mathrm{Cu}, 5 \mathrm{Ti}+3 \mathrm{Si}$ mixture, and $\mathrm{Ti}_{5} \mathrm{Si}_{3}$

\begin{tabular}{|c|c|c|c|}
\hline Thermophysical Property & $\mathrm{Cu}$ & $5 \mathrm{Ti}+3 \mathrm{Si}$ & $\mathrm{Ti}_{5} \mathrm{Si}_{3}$ \\
\hline$\rho\left(\mathrm{kg} / \mathrm{m}^{3}\right)$ & 8930 & 3850 & 4315 \\
\hline $\mathbf{k}(\mathrm{W} / \mathrm{mK})$ & 398 & 36.5 & 15.2 \\
\hline $\mathrm{C}_{0}(\mathrm{~J} / \mathrm{kgK})$ & 386 & 570 & 773 \\
\hline$\alpha\left(\mathrm{m}^{2} / \mathrm{s}\right)$ & $1.15 \times 10^{-4}$ & $1.66 \times 10^{-5}$ & $4.56 \times 10^{-6}$ \\
\hline
\end{tabular}
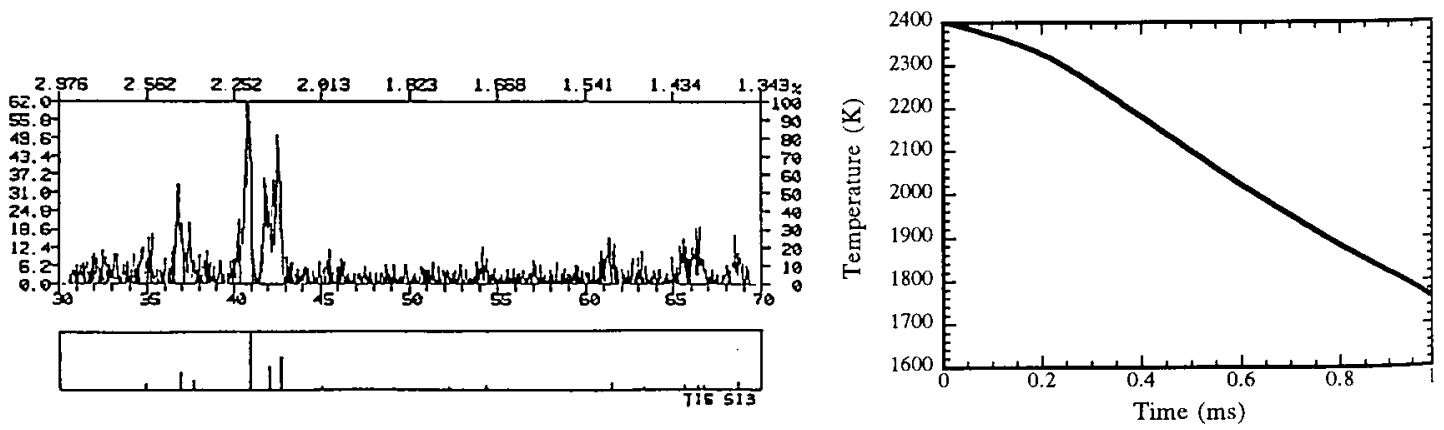

Figure 3: X-ray diffraction analysis results of products.

Figure 4: Predicted temperature profile inside the unreacted triangular regions (points $A$ in Fig. 1(b)). 


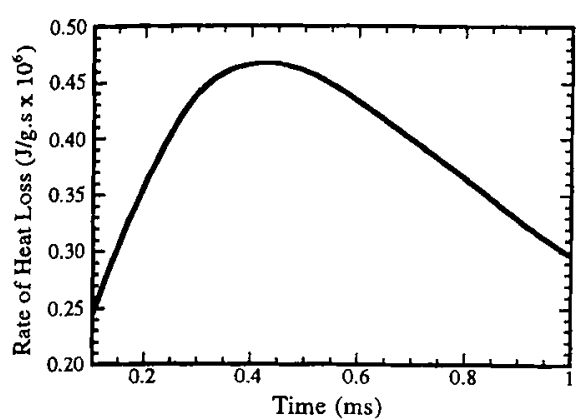

Figure 5 Predicted rate of heat loss inside the unreacted triangular region (points $A$ in Fig. 1(b)).

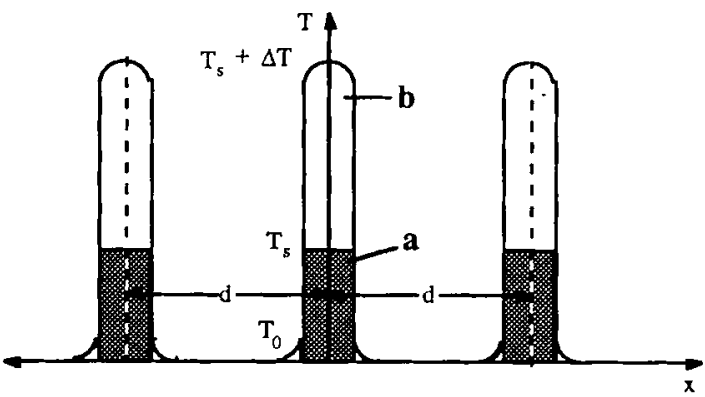

Figure 6 Schematic one-dimensional model of periodic "hot spots": (a) temperature distribution after shear localization; (b) temperature distribution after chemical reaction initiation.

Fig. 5 shows the time-dependent rate of heat loss. The maximum $\dot{Q}_{\text {loss }}$ is equal to $4.5 \times 10^{5} \mathrm{~J} / \mathrm{g} \cdot \mathrm{s}$. Therefore, the reaction rate for the Ti-Si powder mixtures should be less than this value.

\section{PERIODIC “HOT SPOT” MODEL}

From the experimental results, it can be seen that distribution of shear localization regions is periodic. Therefore, a model for the idealized periodic distribution of "hot spots" in reactive powder mixtures is proposed. Figure 6 is a schematic illustration of the idealized model. The "hot" shear localization regions (shaded area) have a width equal to $\delta(10 \sim 20 \mu \mathrm{m})$ and a spacing $\mathrm{d}(\sim 600 \mu \mathrm{m})$. The temperature inside the shear localization regions increases to $\mathrm{T}_{\mathrm{s}}\left(=\mathrm{T}_{0}+\Delta \mathrm{T}_{\mathrm{s}}\right)$ during deformation. If $\mathrm{T}_{\mathrm{s}}$ is sufficiently high, the chemical reactions between reactive powder mixtures can be initiated. At this time, the reaction heat is released and the temperature increases by some amount $\Delta \mathrm{T}$. Therefore, the temperature inside the shear localization regions is $T_{s}+\Delta T$. However, the surrounding powder mixtures are at a lower temperature $(T=$ $\left.\mathrm{T}_{0} \approx 300 \mathrm{~K}\right)$. The heat will be conducted to the surrounding. The conservation of energy for this model is given by:

$$
\rho C_{p} \frac{\partial T}{\partial t}=k \frac{\partial^{2} T}{\partial x^{2}}+\rho Q \frac{\partial \eta}{\partial t}+\frac{\partial(\tau \gamma)}{\partial t}, \quad \frac{\partial \eta}{\partial t}=K_{0}(1-\eta)^{n} e^{-\frac{E}{R T}}
$$

where $\mathrm{k}$ is the thermal conductivity $(\mathrm{W} / \mathrm{m} \cdot \mathrm{K}), \mathrm{K}_{0}$ is the reaction-rate constant $\left(\mathrm{s}^{-1}\right), \mathrm{n}$ is the order of the reaction, $\mathrm{E}(\sim 200 \mathrm{~kJ} / \mathrm{mol}[19])$ is the activation energy for the reaction, and $\mathrm{R}$ is the universal gas constant. For the sake of simplicity, the following assumptions are made:

(a) The shear localization and the chemical reaction do not occur simultaneously, i.e. they occur sequentially.

(b) Define $t=0$ when $T_{s}(\approx 2400 \mathrm{~K})$ is reached. Therefore, the deformation work term in Eqn. 5 can be eliminated and the initial condition defined as:

$$
\begin{aligned}
& \rho C_{p} \frac{\partial T}{\partial t}=k \frac{\partial^{2} T}{\partial x^{2}}+\rho Q \frac{\partial \eta}{\partial t}, \\
& \text { I.C. } T(x, 0)=\left\{\begin{array}{lll}
T_{s} & \text { at } & 0 \leq x<\delta / 2 d-\delta / 2<x \leq d \\
T_{0} & \text { d } & \delta / 2 \leq x \leq d-\delta / 2
\end{array}\right.
\end{aligned}
$$

(c) The boundary conditions are defined as:

$$
\text { B.C. } \quad \frac{\partial \mathrm{T}(\mathrm{x}, \mathrm{t})}{\partial \mathrm{x}}=0 \quad \text { at } \quad x=0, d / 2, d
$$

(d) Thermophysical properties are assumed constant.

Assuming $n=1$, the temperature distribution with varying time is shown in Figs. 7. Fig 7(a) shows that at $\mathrm{T}_{\mathrm{s}} \approx 2400 \mathrm{~K}$, the reaction can propagate throughout the entire specimen. The maximum temperature in shear bands is equal to approximately $4000 \mathrm{~K}$. It is consistent with the calculated adiabatic temperature. At $T_{s} \approx$ 

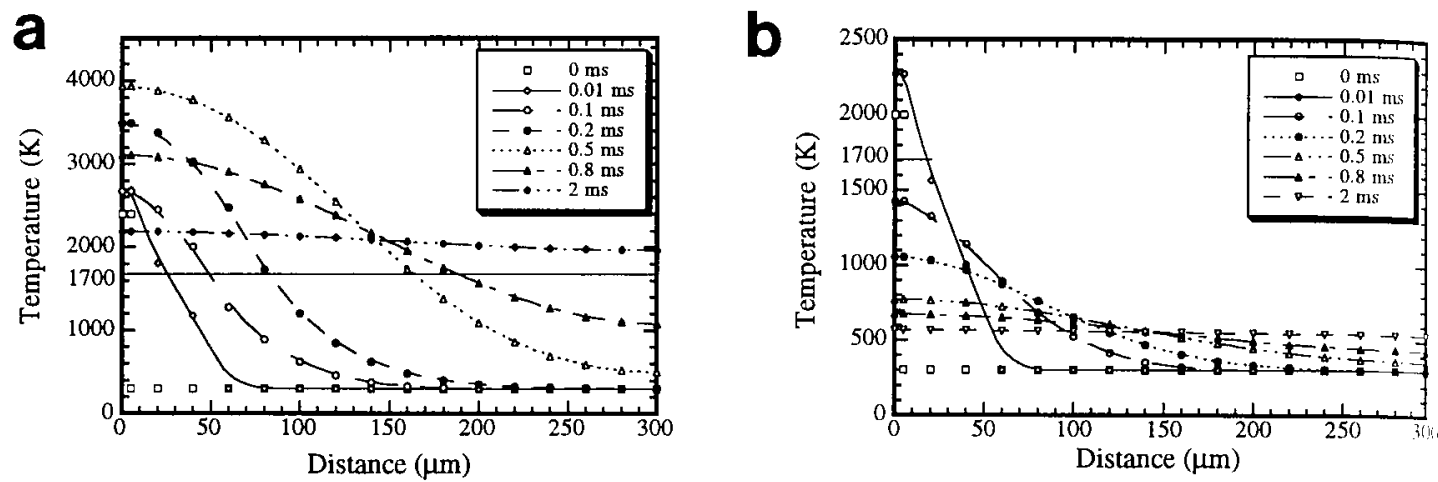

Figure 7 Temperature distribution calculated by periodic "hot spots" model: (a) $\mathrm{T}_{\mathrm{s}} \approx 2400 \mathrm{~K}$; (b) $\mathrm{T}_{\mathrm{s}} \approx 2000 \mathrm{~K}$.

$2000 \mathrm{~K}$, the reaction only can propagate a short distance (Fig $7(\mathrm{~b})$ ). Therefore, the critical temperature, $\mathrm{T}_{\text {. }}$. $\left(2000 \mathrm{~K}<\mathrm{T}_{\mathfrak{c}}<2400 \mathrm{~K}\right)$ created by shear deformation can be predicted by this model.

\section{ACKNOWLEDGMENTS}

This research is supported by the U.S. Army Research Office, Contract DAAH-04094-G-031 and by the U.S. Office of Naval Research, Contract N00014-94-1-1040 (program officer Dr. J. Goldwasser). The help of M.P. Bondar, Y. Lukyanov (IGIL, Novosibirsk), and S.M. Usherenko (RIIP, Minsk) in conducting experiments is gratefully acknowledged. We thank Dr. E. Olevsky for help with the heal transfer and reaction computations.

\section{REFERENCES}

[1] Bridgman P.W., Phys. Rev., 48 (1935) 825.

[2] Vereshchagin L.F., E.V. Zubova, and V.A. Shapochkin, Pribori, Tekhn. Esperim., 5 (1960) 89.

[3] Teller E., J. Chem. Phys., 36 (1962) 901.

[4] Enikolopyan N.S., A.A. Mkhitaryan, A.S. Karagezyan., and A.A. Khzardzhyan, Dok. Akad. Nauk. SSSR, 292, (1987), 887.

[5] Dremin A.N. and O.N. Breusov, Russian Chem. Rev., 37 (5) (1968) 392.

[6] Yu L.H., W. Nellis, M.A. Meyers, and K.S. Vecchio, in "Shock Compression of Condensed Matter1993", S.C. Schmidt, J.W. Shaner, G.A. Samara, M. Ross eds., Am. Inst. Physics, (1994), 1291.

[7] Meyers M.A., S.S. Batsanov, S.M. Gavrilkin, H.C. Chen, J.C. LaSalvia, and F.D.S. Marquis, Mater. Sci. and Eng. A, 201 (1995) 150.

[8] Nesterenko V.F., M.A. Meyers, H.C. Chen, and J.C. LaSalvia, Appl. Phys. Lett., 65 (24), (1994) 3069.

[9] Nesterenko V.F., M.A. Meyers, H.C. Chen, and J.C. LaSalvia, Metall. and Mater. Trans., 26A. (1995) 2511.

[10] Nesterenko V.F., M.A. Meyers, H.C. Chen, and J.C. LaSalvia, in "High-Pressure Science and Technology - 1995", S.C. Schmidt and W.C. Tao eds., Am. Inst. Physics (1996), 713.

[11] Nesterenko V.F., M.P. Bondar, and I.V. Ershov, in "High-Pressure Science and Technology 1993", S.C. Schmidt, J.W. Shaner, G.A. Samara, and M. Ross eds., Am. Inst. Physics, New York, (1994) 1172.

[12] Meyers M.A., L.H. Yu, and K.S. Vecchio, Acta Met. et Mat., 42 (1994) 715.

[13] Vecchio K.S., L.H. Yu, and M.A. Meyers, Acta Met. et Mat., 42 (1994) 701.

[14] Knacke O., O. Kubashewski, and K. Hesselmann, "Thermochemical Properties of Inorganic Substances", Springer-Verlag, New York, (1991).

[15] Merzhanov A.G., Fiz. Goreniya I Vzryva, 9 (1), (1973) 4.

[16] Kosolapova T. Ya., "Handbook of High Temperature Compounds: Properties, Production, Applications", Hemisphere Publ. (1990).

[17] Nicolet M.-A. and S.S. Lau, "VLSI Electronics: Mictrostructure Science" Vol. 6, Academic Press (1983).

[18] LaSalvia J.C., D.K. Kim, R.A. Lipsett, and M.A. Meyers, Metall. and Mater. Trans., 26A (1995) 3001.

[19] Wang L.L. and Z.A. Munir, Metall. and Mater. Trans., 26B, (1995) 595. 